\title{
Short admission in an emergency psychiatry unit can prevent prolonged lengths of stay in a psychiatric institution
}

\section{Internação breve em unidade de emergência psiquiátrica pode prevenir permanência prolongada em instituições psiquiátricas}

\author{
Régis Eric Maia Barros, ${ }^{1}$ João Mazzoncini de Azevedo Marques, ${ }^{1}$ Isabela Panzeri Carlotti, ${ }^{1}$ Antonio Waldo \\ Zuardi, ${ }^{1}$ Cristina Marta Del-Ben'
}

${ }^{1}$ Division of Psychiatry, Department of Neurosciences and Behavior, Faculty of Medicine of Ribeirão Preto, Universidade de São Paulo (USP), Ribeirão Preto, SP, Brazil

\begin{abstract}
Objective: Characterize and compare acute psychiatric admissions to the psychiatric wards of a general hospital (22 beds), a psychiatric hospital (80) and of an emergency psychiatry unit (6). Method: Survey of the ratios and shares of the demographic, diagnostic and hospitalization variables involved in all acute admissions registered in a catchment area in Brazil between 1998 and 2004. Results: From the 11,208 admissions, $47.8 \%$ of the patients were admitted to a psychiatric hospital and $14.1 \%$ to a general hospital. The emergency psychiatry unit accounted for $38.1 \%$ of all admissions during the period, with a higher variability in occupancy rate and bed turnover during the years. Around $80 \%$ of the hospital stays lasted less than 20 days and in almost half of these cases, patients were discharged in 2 days. Although the total number of admissions remained stable during the years, in 2004, a $30 \%$ increase was seen compared to 2003. In 2004, bed turnover and occupancy rate at the emergency psychiatry unit increased. Conclusion: The increase in the number of psychiatric admissions in 2004 could be attributed to a lack of new community-based services available in the area beginning in 1998. Changes in the health care network did affect the emergency psychiatric service and the limitations of the community-based network could influence the rate of psychiatric admissions.
\end{abstract}

Descriptors: Length of stay; Hospital care; Psychiatric emergency services; Residence time; Deinstitutionalization

\section{Resumo}

Objetivo: Caracterizar e comparar internaçôes psiquiátricas agudas em alas psiquiátricas no hospital geral (22 leitos), hospital psiquiátrico (80) e emergência psiquiátrica (6). Método: Foram analisadas todas as internaçôes agudas entre 1998 e 2004 na regiāo do estudo, com razōes e proporçôes de variáveis demográficas, diagnósticas e das hospitalizaçôes. Resultados: Das 11.208 internaçôes, 47,8\% foram no hospital psiquiátrico e 14,1\% no hospital geral. A emergência psiquiátrica realizou $38,1 \%$ das internaçôes no periodo, com grande variabilidade da taxa de ocupação e giro leito durante os anos. Cerca de $80 \%$ das internaçôes foram menores que 20 dias, com metade destas resolvidas em dois dias. O número total das internaçôes permaneceu estável durante os anos, mas em 2004 ocorreu um aumento de $30 \%$ em relação a 2003. O giro leito e a taxa de ocupaçāo na emergência psiquiátrica aumentaram em 2004. Conclusão: O aumento das internaçôes psiquiátricas em 2004 pode estar ligado ao não surgimento de novos serviços extra-hospitalares desde 1998. O serviço de emergência psiquiátrica refletiu mudanças na rede de saúde e as limitaçôes da rede de saúde extra-hospitalar podem ter influenciado a taxa de internaçôes psiquiátricas.

Descritores: Tempo de internação; Assistência hospitalar; Serviço de emergência psiquiátrica, Tempo de permanência; Desinstitucionalização

\section{Introduction}

The 1990s were marked by significant changes in mental health policies and practices, as seen throughout the world, and by the guidelines for psychiatric care proposed by the World
Health Organization influenced various countries. ${ }^{1}$ In Brazil, governmental polices favored the gradual closing of psychiatric hospitals $(\mathrm{PH})$ and the replacement of prolonged stays at
Submitted: June 2, 2009

Accepted: September 29, 2009

\section{Correspondence}

Régis Eric Maia Barros

Divisão de Psiquiatria

Departamento de Neurociências e Ciências do Comportamento

Faculdade de Medicina de Ribeirão Preto - Universidade de São Paulo

Avenida Bandeirantes, 3900

14049-900 Ribeirão Preto, SP, Brasil

Phone: (+55 16) 3602-2607 Fax: (+55 16) 3602-2544

E-mail: regisbarros@usp.br 
psychiatric hospitals with other forms of treatments based on community mental health services and admissions to psychiatric units at general hospitals. ${ }^{2}$ The number of emergency units (EP) and psychiatric wards at general hospitals $(\mathrm{GH})$ grew over the past two decades, but most of these are still located in regions that are economically developed (south and southeast) and often associated with teaching institutions. ${ }^{3,4}$

The catchment area of Ribeirão Preto, located in the state of São Paulo, Brazil, comprises 26 municipalities with an estimated population of 1,200,000 inhabitants and a per capita income of U\$5,000 a year. ${ }^{5}$ Since 1990 , the local mental health authorities have made adjustments to the mental health polices proposed by the National Ministry of Health by assigning hospital psychiatric care over to an organized network of community-based services and providing an academic emergency service for referral for all emergency psychiatric services in the area. ${ }^{6}$

In 1990, the region offered 1,118 psychiatric beds, mostly found in traditional psychiatric hospitals. Occupancy rates were as high as $96 \%$, with long hospitalization periods and many re-admissions. ${ }^{7}$ Beginning in 1995, as a result of the effective application of the new polices, a significant reduction in the number of psychiatric beds for acute admissions (around 100 beds) was seen, followed by a significant increase in community-based services. Although the number of psychiatric beds decreased dramatically, the occupation rate was no higher than $70 \%$, suggesting that the previous rates of psychiatric admissions were artificial and did not reflect real clinical hospitalization needs. ${ }^{8}$

Beds for acute psychiatric cases were redistributed into three different modalities of hospitalization, all under the umbrella of the public healthcare system: a traditional $\mathrm{PH}$, psychiatric wards at a GH, and an EP located at a general emergency hospital. Working in an integrated way, these units became the building blocks of a control center for psychiatric admissions; however, the decision as to whether hospitalization was needed was primarily taken by the EP staff. ${ }^{9}$ The clinical criteria for the decision to admit a patient were essentially based on the psychiatric condition, availability of beds at each hospital and on the need for clinical support in the case of co-morbidities.

With the purpose of profiling and assessing the dynamics of the mental health network of the catchment area of Ribeirão Preto, a retrospective and descriptive study was carried out in which all psychiatric hospitalizations recorded in a seven-year period (1998-2004) were evaluated. More specifically, this study aimed at evaluating and comparing different hospitalization modalities: psychiatric wards at a general hospital, a traditional psychiatric hospital and a psychiatric emergency ward. A clinical and demographic characterization of the hospitalized population was carried out, and the hospitalization features of each unit were also assessed.

\section{Method}

Data from the medical records of all the patients admitted for acute hospitalization in the catchment area of Ribeirão Preto in the state of São Paulo in the period 1998-2004 were used. The
108 psychiatric beds reserved for acute admission available in the region were found to be located at a traditional $\mathrm{PH}$ ( 80 beds distributed into three wards, namely male, female and male drug users with 30, 30 and 20 beds respectively), at an EP ( 6 beds) and in the psychiatric wards of a GH (14 beds in 2000; 22 beds in the following years).

Data gathered on the three units were used to compose a single database so that information relating to hospitalizations could be reliably crossed and analyzed. This process was carried out by an experienced system analyst and a psychiatrist familiarized with the mental health network. The database was built based on the number of hospitalizations, and the factors that could help determine errors in the total number of hospitalizations such as temporary discharges and transfers among infirmaries were also studied. Hospitalizations in each service were considered based on the service from which the patient was last discharged from. For instance, a patient who had been admitted into the emergency room and had stayed there for 2 days but was then transferred to the ward of a general hospital was included in the database as an admission to a general hospital. In general, the length of stay in the EP remained at less than 48 hours, regardless of the hospital to which the patient was transferred (PH or GH).

The demographic variables analyzed included age, marital status, occupation, and discharging institution. Psychiatric diagnoses were categorized according to the International Classification of Diseases ${ }^{10}$ considering the diagnosis registered at the time of discharge. With respect to admission according to one of the three possible modalities, we analyzed the number of hospitalizations, bed turnover (number of patients/bed/year), occupation rate and length of hospitalization.

Numbers and ratios for each variable according to the different services were compiled. Ratios in relation to the index year (1998) and the frequencies of each variable were used as basis for data analysis. Calculations for bed turnover and occupancy rates were done based on the number of beds available in each unit.

The project was approved by the Research Ethics Committee of the Faculty of Medicine of Ribeirão Preto, Universidade de São Paulo (protocol no ${ }^{\circ} .8216 / 05$ )

\section{Results \\ 1. Demographics}

As seen in Table 1, most psychiatric admissions in the catchment area of Ribeirão Preto between 1998 and 2004 involved male patients $(56.0 \%$,) aged between 20 to 39 (53.9\%), without a stable marriage or marital tie $(66.1 \%)$. Most patients were professionally inactive $(64.3 \%)$ and came from municipalities within the region (97.7\%). The profile of patients admitted to each hospital was different. The psychiatric wards of the general hospital admitted a higher ratio of younger and female patients than the psychiatric hospital.

\section{Diagnoses}

Diagnoses of psychoactive substance-related disorders, psychotic disorders, mood disorders and personality disorders prevailed in all the healthcare services included in this survey. The diagnosis 
Table 1 - Demographic features and diagnoses of psychiatric admissions to hospital services in the region of Ribeirão Preto between 1998 and 2004, according to the hospital service which discharged the patient

\begin{tabular}{|c|c|c|c|c|c|c|c|c|}
\hline & \multicolumn{2}{|c|}{ Emergency service } & \multicolumn{2}{|c|}{ General hospital } & \multicolumn{2}{|c|}{ Psychiatric hospital } & \multicolumn{2}{|c|}{ Total } \\
\hline & $\mathbf{n}$ & $\%$ & $\mathbf{n}$ & $\%$ & $\mathbf{n}$ & $\%$ & $\mathbf{n}$ & $\%$ \\
\hline \multicolumn{9}{|l|}{ Demographic features } \\
\hline 20 to 39 & 2276 & $(54.0)$ & 702 & $(45.0)$ & 3034 & $(56.6)$ & 6012 & $(53.9)$ \\
\hline Single & 2935 & $(68.8)$ & 1056 & $(67.0)$ & 3420 & $(63.8)$ & 7411 & $(66.1)$ \\
\hline Professionally inactive & 2567 & $(60.1)$ & 1050 & $(66.6)$ & 3590 & $(67.0)$ & 7207 & (64.3) \\
\hline \multicolumn{9}{|l|}{ Diagnosis } \\
\hline Substance related disorder & 1216 & $(28.5)$ & 109 & $(6.9)$ & 1325 & $(24.7)$ & 2650 & $(23.6)$ \\
\hline Psychotic disorders & 867 & $(20.3)$ & 508 & $(32.2)$ & 1952 & $(36.4)$ & 3327 & $(29.7)$ \\
\hline Mood Disorders & 840 & (19.7) & 663 & $(42.0)$ & 1351 & $(25.2)$ & 2854 & $(25.5)$ \\
\hline Personality Disorders & 556 & $(13.0)$ & 95 & $(6.0)$ & 341 & $(6.4)$ & 992 & $(8.9)$ \\
\hline Others & 790 & (18.5) & 202 & $(12.8)$ & 393 & $(7.3)$ & 1385 & $(12.4)$ \\
\hline \multicolumn{9}{|l|}{ Length of stay } \\
\hline 3 to 10 days & 284 & $(6.7)$ & 655 & $(41.5)$ & 1916 & $(35.7)$ & 2855 & $(25.5)$ \\
\hline 11 to 20 days & 12 & $(0.3)$ & 275 & (17.4) & 1615 & $(30.1)$ & 1902 & $(17.0)$ \\
\hline 21 to 30 days & 2 & $(0.1)$ & 146 & $(9.3)$ & 815 & $(15.2)$ & 963 & $(8.6)$ \\
\hline More than 30 days & 1 & $(0.0)$ & 424 & $(26.9)$ & 846 & $(15.8)$ & 1271 & $(11.3)$ \\
\hline
\end{tabular}

of substance-related disorders was the cause of around $25 \%$ of the admissions to the $\mathrm{PH}$ and to the EP. Approximately one third of the patients admitted to both the PH and the GH had been diagnosed with a psychotic disorder. However, in terms of the share of patients diagnosed with a mood disorder, including both mania and depressive episode, in a balanced way, the GH registered a higher share (42.0\%) compared to the PH (25.2\%).The EP had a wider variety of diagnoses (classified as "others") and personality disorders in comparison to admissions to the GH and PH.

\section{Total hospitalizations}

Between January 1998 and December 2004, 5,362 patients were hospitalized, totaling the 11,208 psychiatric hospitalizations due to readmissions in the region of Ribeirão Preto. Around half of these admissions $(5,362 ; 47.8 \%)$ occurred at the $\mathrm{PH}$, followed by $4,269(38.1 \%)$ at the EP and 1,577 (14.1\%) at the GH.

Figure 1 shows the total number of admissions and the percentage of hospitalizations in each service. In 1998, the total number of admissions reached 1,506, remaining stable until 2003, when a slight increase was observed (1,613 admissions). However, in 2004, when 2,101 admissions were registered, there was a $30 \%$ increase in the number of admissions compared to the previous year.

Hospitalizations in the $\mathrm{PH}$ increased over time, except for 2001 even though PH accounted for the largest share i.e., more than $40 \%$ of the total number of hospitalizations registered in the region in 2001.

Starting in 2000, the number of psychiatric hospitalizations at the GH increased significantly, with 2.5 times more admissions in 2001-2002 than in the index year. Although hospitalizations at the GH decreased in the more recent years, the total number of hospitalizations per year was still twice that which was registered for the index year. Changes in the number of admissions to the $\mathrm{GH}$ from 2000 are due to an increase in the number of beds from 14 to 22, where the new beds were reserved for short-stay admissions.

The EP accounted for most hospitalizations in 1998-1999. However, there was a progressive reduction in the number of hospitalizations in this service concomitant with an increase in hospitalizations at the GH and the PH. In 2004, consistent with the increase in total hospitalizations within the region, there was an increase in hospitalizations at the EP that equaled the number of hospitalizations in the index year.

\section{Length of hospitalization}

Table 1 shows that, of the 11,208 hospitalizations registered between 1998 and 2004, around 80\% lasted less than 20 days, where almost half of the patients were discharged in 2 days. Just $11.3 \%$ of the admissions lasted over 30 days. When hospitalization units were analyzed separately, differences between them came to the surface. Over $90 \%$ of all hospitalizations at the EP lasted less than two days and almost all hospitalizations lasted less than 10 days. At the $\mathrm{GH}$, over $50 \%$ of all hospitalizations lasted less than 20 days, although $26.9 \%$ lasted more than 30 days. At the $\mathrm{PH}$, short and medium-term hospitalizations i.e., 3 to 10 days $(35.7 \%)$ and 11 to 20 days (30.1\%) respectively prevailed, and hospitalization times exceeding 30 days were only observed in $15.8 \%$ of the admissions.

\section{Bed turnover}

As shown in Table 2, the EP experienced the highest bed turnover, although a variation did take place depending on the year. The bed turnover rate dropped between 2000 and 2003 and increased once again in the final year of the study. The opposite situation was seen with respect to the 


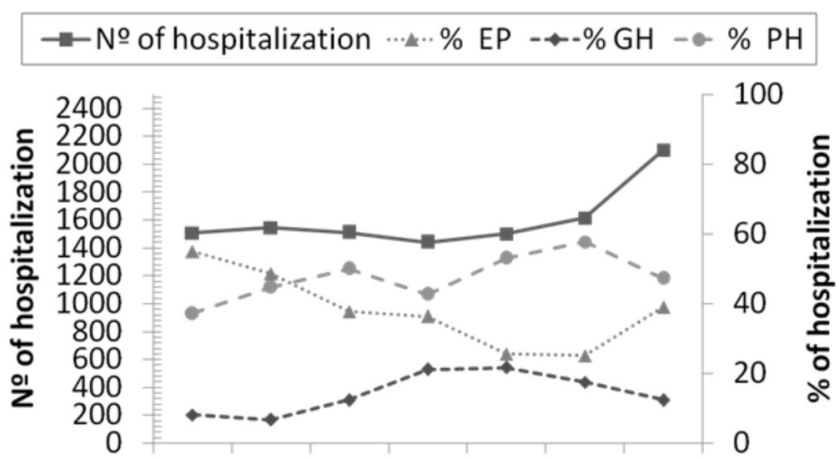

1998199920002001200220032004

Year

Figure 1 - Total number of admissions and the percentage of hospitalizations in each service, between January 1, 1998 and December 31, 2004 in the region of Ribeirão Preto, according to the hospital service from which the patient was last discharged. $\mathrm{EP}=$ Emergency Psychiatric Unit; $\mathrm{PH}=$ Traditional Psychiatric Hospital; GH = Psychiatric Wards in General Hospital.

bed turnover at the GH, which increased in 2000. At the $\mathrm{PH}$, a yearly increase in bed turnover was observed, especially in 2003 and 2004, when the numbers were similar to those observed for the GH.

\section{Occupancy rate}

Figure 2 shows the occupancy rate per year of the three units. The beds available at the GH always had occupancy rates of at least $80 \%$ in all the years surveyed. The occupancy rate of the $\mathrm{PH}$ increased progressively over the years and, in 2003 and 2004, its occupancy rate equaled that of the GH. A decrease was observed in the occupancy rate of the EP starting in 1999, however, this rate increased in 2004.

\section{Discussion}

This descriptive study has provided an evaluation of all the psychiatric admissions that were registered in a specific catchment area throughout a long period of 7 years and compared the different modalities of admissions. Despite the availability of many descriptive studies on psychiatric hospitalizations ${ }^{11-18}$ few have worked with large and representative samples collected from large regions involving more than one hospitalization unit, ${ }^{19-21}$ thus providing a more encompassing view of the mental health network.

The demographic profile of the patients admitted to the psychiatric units under study is similar to those described in other studies. ${ }^{22,23}$ The majority of the people admitted to these units were

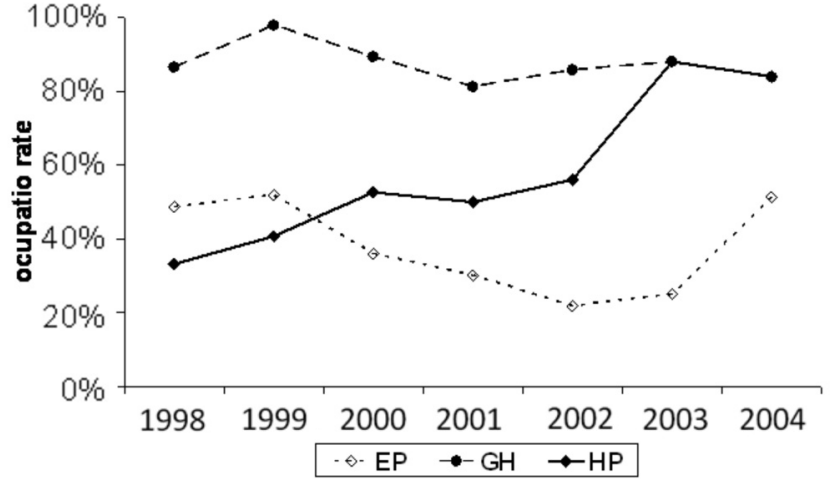

Figure 2 - Distribution of the occupancy of psychiatric beds available in the region of Ribeirão Preto between January 1, 1998 and December 31, 2004, according to hospital service which ultimately discharged the patient. $E P=$ Emergency Psychiatric Unit; PH = Traditional Psychiatric Hospital; GH = Psychiatric Wards in General Hospital.

young, male, unemployed, and did not have any conjugal ties. The higher proportion of females admitted to the general hospital could be traced back to a slightly higher number of beds (two in total) designated for female patients in this unit. The higher proportion of younger patients in the GH could also be attributed to the tendency of the emergency room staff to avoid referring first episode psychosis cases to admission to a psychiatric hospital, as described earlier. ${ }^{24}$ Specifically in the case of the EP, although there are no official policies contemplating this, there is a clinical preference of sending patients who are experiencing a first episode of a severe mental disorder to a general hospital because of the resources that are available there to conduct a differential diagnosis.

The presence of a higher number of patients diagnosed with substance-related disorders at the $\mathrm{PH}$ compared to the GH can be explained by the fact that the mental health unit specialized in long-term treatment for these psychiatric patients is located at the $\mathrm{PH}$. The same is true for the high proportion of substancerelated disorders diagnosed in the EP, since the management of withdrawal syndromes is conducted mainly in the EP.

The proportion of admissions due to psychotic disorders is similar in the $\mathrm{PH}$ and in the GH, but the same is not true for the diagnosis of mood disorder. There is no specialized unit for the treatment of mood disorders in the GH and, therefore, this data can not be explained by the organization of the network of psychiatric services, as is the case with substance-related disorders. Since the services included in this study have no policies or guidelines recommending that patients suffering from mood disorders be admitted preferably to the general hospital,

Table 2 - Total bed turnover seen in hospitalization services between January 1, 1998 and December 31, 2004 in the region of Ribeirão Preto, according to the hospital service from which the patient was last discharged

\begin{tabular}{lccccccc}
\hline & $\mathbf{1 9 9 8}$ & $\mathbf{1 9 9 9}$ & $\mathbf{2 0 0 0}$ & $\mathbf{2 0 0 1}$ & $\mathbf{2 0 0 2}$ & $\mathbf{2 0 0 3}$ & $\mathbf{2 0 0 4}$ \\
\hline Emergency service & 137.7 & 125.2 & 94.7 & 87.0 & 63.7 & 67.2 & 136.2 \\
General hospital & 8.7 & 7.4 & 11.6 & 13.8 & 14.7 & 12.7 & 11.7 \\
Psychiatric hospital & 7.0 & 8.6 & 9.4 & 7.7 & 9.9 & 11.6 & 12.8 \\
\hline
\end{tabular}


we could considered that the data on mood-disorder diagnoses could be explained by an unconscious preference on the part of the emergency room staff related at brief admission in $\mathrm{GH}$ for dealing with mood disorders instead of schizophrenia and other psychotic disorders. $^{25}$

Considering the number of beds available in each service, the number of admissions to the $\mathrm{PH}$ and the $\mathrm{GH}$ is quite expected; the $\mathrm{PH}$ has 80 beds available while the $\mathrm{GH}$ has just 22 . The $\mathrm{PH}$ was responsible for $47.8 \%$ of the total admissions whereas the $\mathrm{GH}$ was responsible for $14.1 \%$ of the total admissions that occurred in the period.

However, the rate of admissions to the EP was clearly unexpected. The EP, which has the lowest number of beds ${ }^{6}$ accounts for about $40 \%$ of all hospitalizations. This means that a high proportion of the patients suffering from acute psychiatric disorders were admitted for a short period of time and then absorbed by the network of community-based services. Effective emergency psychiatric units mitigate the need for longer hospital stays by improving the operation of the network itself. ${ }^{26}$ Furthermore, hospitalization restrictions for cases where a patient really needs to be hospitalized can determine the organization of the service network and of the flow of patients. ${ }^{27}$

The total number of admissions per each year remained practically stable until the last years of the study, probably because of health network organization through hospitalization service. Although the total number of hospitalizations remained stable each year, the distribution of admissions in the various services changed, with a decrease in EPs and an increase in both PH and GH. The increase in $\mathrm{GH}$ admissions is justified by the increase in the number of beds in 2000, but the increase in HP admissions and concomitant reduction in EP admission could also be understood as a gradual deterioration of the condition of patients requiring hospitalization.

The increase in admissions, particularly in 2004, cannot be explained by population changes in the catchment area under study, since the rate of population growth observed was significantly lower than the increase in the rate of psychiatric admissions. ${ }^{5}$ One possible explanation for the change seen in the pattern of psychiatric admissions could be the fact that the progressive increase in the occupancy rate in the $\mathrm{PH}$ reached a ceiling in 2003 and 2004. This absence of beds in the PH and GH resulted in patients needing hospitalization at the EP, regardless of the severity of their condition. Indeed, the increase in total admissions in 2004 occurred in light of increased admissions in the EP. A major source of concern is the risk of readmission shortly after discharge as a direct result of a short hospital stay. ${ }^{28}$ Unfortunately, the way in which our database is set up does not allow us to access the occurrence of new admissions for patients admitted to the emergency room. Therefore, another study will be carried out to deal with this issue in particular.

The progressive deterioration in the condition of hospitalized patients could be due to the fact that no new community-based service has been created in the catchment area of Ribeirão Preto since 1998. Higher hospitalization rates are associated with a shortage of community-based services, as the existence of these treatment modalities has a positive effect on reducing psychiatric admissions. ${ }^{29}$ The assumption that the health care network is overburdened is reinforced by the increase in the number of hospitalizations observed at the emergency psychiatric unit. Effective emergency services can reduce hospitalizations, but they are also represent the main gateway to the system when access to the outpatient network becomes limited. ${ }^{30}$

Nevertheless, we have not been able to identify other factors that could be affecting the follow-up of psychiatric patients relying on community based services. For instance, a decrease in the number of professionals working in the mental health services or shortage of medicines could lead to a new psychotic or mood episode. Additionally, a decrease in the ability of the middle-income population, including an increasing number of elderly people to pay and/or obtain psychiatric intensive care from healthcare services other than that obtained from the public healthcare system could be associated with a greater use of the intensive psychiatric services provided by the Brazilian government. ${ }^{31}$

The hypothesis of an overburdened mental health network is supported by the profiling of bed turnover and occupancy rates. The emergency service had a higher bed turnover in the index year, but this number dropped progressively during the following years, as the bed turnover rate in both the $\mathrm{GH}$ and the $\mathrm{PH}$ increased. However, in 2004, the bed turnover rate in the EP was very similar to that registered in 1998.

The length of stay is a major tool to evaluate mental health care networks. Our data have shown that the majority of psychiatric admissions lasted less than 20 days, although around $11.3 \%$ of the total number of admissions lasted more than a month. Longer hospital stays can be related not only to the severity of the mental disorder but also to non-clinical factors such as the severity of psychosocial stressors, unemployment, and inadequate financial and social resources. ${ }^{31-35}$ Hospitalizations in traditional psychiatric hospitals are expected to last approximately 20 days, while in general hospitals their duration is expected to be shorter than those observed in this study. ${ }^{36,37}$ Again, this can be attributed to the organization of the local network, since usually one of the hospital's wards at the general hospital is in charge of highly complex cases. ${ }^{38}$

\section{Conclusion}

The demographic profile of psychiatric patients admitted according to different modalities of hospitalization is in tune with data described in the literature. The increase in the number of psychiatric admissions observed in 2003, and especially in 2004, seems to be due to limitations of the community-based services network in receiving new patients and/or providing more intensive care to patients suffering from new episodes; given that no services have been established in this region since 1998 Changes that were made to the health care network impacted the emergency service, which accounted for almost $40 \%$ of all psychiatric admissions observed in the period, freeing up psychiatric units designated for more prolonged lengths of stay and stabilizing the mental health network. 


\section{Disclosures}

\begin{tabular}{|c|c|c|c|c|c|c|c|}
\hline $\begin{array}{l}\text { Writing group } \\
\text { member }\end{array}$ & Employment & $\begin{array}{l}\text { Research } \\
\text { grant }^{1}\end{array}$ & $\begin{array}{l}\text { Other research grant or } \\
\text { medical continuous } \\
\text { education }\end{array}$ & $\begin{array}{l}\text { Speaker's } \\
\text { honoraria }\end{array}$ & $\begin{array}{c}\text { Ownership } \\
\text { interest }\end{array}$ & $\begin{array}{l}\text { Consultant/ } \\
\text { Advisory } \\
\text { board }\end{array}$ & Other $^{3}$ \\
\hline $\begin{array}{l}\text { Régis Eric Maia } \\
\text { Barros }\end{array}$ & FMRP & $\begin{array}{l}\text { FAPESP } \\
\text { (Grant number: } \\
\text { 06/51738-6) } \\
\text { Foundation } \\
\text { Waldemar } \\
\text { Barnsley } \\
\text { Pessoa } \\
\end{array}$ & - & - & - & - & - \\
\hline $\begin{array}{l}\text { João Mazzoncini } \\
\text { de Azevedo } \\
\text { Marques }\end{array}$ & FMRP & $\begin{array}{l}\text { FAPESP } \\
\text { CNPq }\end{array}$ & - & - & - & - & - \\
\hline $\begin{array}{l}\text { Isabela Panzeri } \\
\text { Carlotti }\end{array}$ & FMRP & - & - & - & - & - & - \\
\hline $\begin{array}{l}\text { Antonio Waldo } \\
\text { Zuardi }\end{array}$ & FMRP & $\begin{array}{l}\text { FAPESP } \\
\text { CNPq }\end{array}$ & - & - & - & - & - \\
\hline $\begin{array}{l}\text { Cristina Marta } \\
\text { Del-Ben }\end{array}$ & FMRP & $\begin{array}{l}\text { FAPESP } \\
\text { CNPq } \\
\text { CAPES }\end{array}$ & - & - & - & - & - \\
\hline \multicolumn{8}{|c|}{$\begin{array}{l}\text { * Modest } \\
\text { ** Significant } \\
\text { *** Significant. Amounts given to the author's institution or to a colleague for research in which the author has participation, not directly to the } \\
\text { author. } \\
\text { Note: FMRP = Faculdade de Medicina de Ribeirão Preto; FAPESP = Fundação de Amparo à Pesquisa do Estado de São Paulo; CNPq = } \\
\text { Conselho nacional de Desenvolvimento Científico e Tecnológico; CAPES = Coordenação de Aperfeiçoamento de Pessoal de Nivel Superior. } \\
\text { For more information, see Instructions for authors. }\end{array}$} \\
\hline
\end{tabular}

References

1. World Health Organization - WHO. Mental health care in developing countries: a critical appraisal of research findings. Geneva: World Health Organization; 1984. Technical report series, 698.

2. Hirdes A. The psychiatric reform in Brazil: a (re)view. Ciênc Saúde Coletiva. 2009; 14(1):297-305

3. Larrobla C, Botega NJ. Restructuring mental health: a South American survey. Soc Psychiatry Psychiatr Epidemiol. 2001;36(5):256-9.

4. Botega NJ. Psychiatric Units in Brazilian General Hospitals: a growing philanthropic field. Int J Soc Psychiatry. 2002;48(2):97-102.

5. Instituto Brasileiro de Geografia e Estatística - IBGE. Censo Populacional 2004. [citado 29 julho 2009]. Disponível em: http://www.ibge.gov.br/

6. Brasil. Presidência da República. Secretaria Nacional de Assistência à Saúde. Portaria n.224; 1992. Diário Oficial da União, Brasília (DF).1992; Seção 1: 224.

7. Brasil. Ministério da Saúde. Secretaria Estadual de Saúde. Programa de Saúde Mental. Direção Regional de Saúde de Ribeirão Preto SP: Ministério da Saúde; 1997.

8. Del Ben CM, Marques JM, Sponhoz A Jr, Zuardi AW. Mental health policies and changes in the emergency services demand. Rev Saude Publica. 1999;33(5):470-6.

9. Santos MESB, do Amor JA, Del Ben CM, Zuardi AW. Psychiatric emergency service in a school general hospital: a prospective study. Rev Saude Publica. 2000;34(5):468-74

10. World Health Organization - WHO. ICD-10 Classification of mental and behavioral disorders. Geneva: World Health Organization; 1992.

11. Maden A, Rutter S, McClintock T, Friendship C, Gunn J. Outcome of admission to a medium secure psychiatric unit. I. Short- and long-term outcome. Br J Psychiatry. 1999;175:313-6.

12. Farragher B, Walsh N. Joint care admissions to a psychiatric unit: a prospective analysis. Gen Hosp Psychiatry. 1998; 20(2): 73-7.

13. Clarke P, Hafner RJ, Holme G. The brief admission unit in emergency psychiatry. J Clin Psychol. 1997;53(8):817-23.

14. Warneke L. A psychiatric intensive care unit in a general hospital setting. Can J Psychiatry. 1986;31(9):834-7.

15. Holmes J, Bentley K, Cameron I. A UK survey of psychiatric services for older people in general hospitals. Int J Geriatr Psychiatry. 2003;18(8):716-21.

16. Hickling FW, Mccallum M, Nooks l, Rodgers-Johnson P. Treatment of acute schizophrenia in open general medical wards in Jamaica. Psychiatr Serv. 2000;51(5):659-63.

17. Hutchinson G, Ramcharan C, Guany K. Gender and ethnicity in first admission to a psychiatric unit in Trinidad. West Indian Med J. 2003;52(4):300-3.

18. Pisa H, Pedace M, Ruiz M, Vairo C, Finkelsztein C, Job A, Matusevich D. Psychogeriatric unit within a General Hospital. Descriptive analysis of outpatient assessment, diagnosis and treatment. Vertex. 2006;17(68): 254-9.

19. Rabelo AR, Modesto TN, Rabelo MM, Rodrigues BM, Melo A. Social and Morbidity Characteristics of all In-patients of the Psychiatric and General Hospital into the Public Netservices in the State of Bahia-Brazil. Rev Baiana Saude Publica. 2003;27(1/2):38-49.

20. Mattioni T, Di Lallo D, Roberti R, Miceli M, Stefani M, Maci M, Perucci CA. Determinants of psychiatric inpatients admission to general hospital psychiatric wards: an epidemiological study in a region of central Italy. Soc Psychiatry Psychiatr Epidemiol. 1999;34(8): 425-31.

21. Maylath E, Seidel J, Werner B, Schlattmann P. Geographical analysis of the risk of psychiatric hospitalization in Hamburg from 1988-1994. Eur Psychiatry. 1999;14(8):414-25.

22. Brenner MK, Cardoso VM, Oliveira RLV, Fensterseifer GP, Barraz ACG, Boeira LB, Barros VC. Changes in the hospitalized clients in psychiatric hospital. J Bras Psiq. 1999;48(9):415-20.

23. Strejilevich S, Chan M, Triskier F, Orgambides S. Operative of a psychiatric internation unit in a general hospital of health public system in Buenos Aires City. Vertex. 2002;13(48):85-92.

24. Bachrach LL. General hospital psychiatry and deinstitutionalization: a systems view. Gen Hosp Psychiatry. 1985;7(3):239-48.

25. Cotton PG, Bene-Kociemba A, Cole R. The effect of deinstitutionalization on a general hospital's inpatient psychiatric service. Hosp Community Psychiatry. 1979;30(9):609-12.

26. Oyewumi LK, Odejide O, Kazarian SS. Psychiatric emergency services in a Canadian city: I. Prevalence and patterns of use. Can J Psychiatry. 1992;37(2):91-5.

27. Holloway F. Need in community psychiatry: a consensus is required. Psychiatr Bull. 1994;18:321-3.

28. Oldham JM, Lin A, Breslin L. Comprehensive psychiatric emergency services. Psychiatry Q. 1990;61(1):57-67. 
29. Lehman AF, Dixon LB, Kernan E, DeForge BR, Postrado LT. A randomized trial of assertive community treatment for homeless persons with severe mental illness. Arch Gen Psychiatry. 1997;54(11):1038-43.

30. Kates N, Eaman S, Santone J, Didemus C, Steiner M, Craven M. An integrated regional emergency psychiatry service. Gen Hosp Psychiatry. 1996;18(4):251-6.

31. Mai FM, Gosselin JY, Varan L, Bourgon L, Navarro JR. Effects of treatment and alternative care on length of stay on a general hospital psychiatric unit--results of an audit. Can J Psychiatry. 1993;38(1):39-45.

32. Lyketsos CG, Dunn G, Kaminsky MJ, Breakey WR. Medical comorbidity in psychiatric inpatients: relation to clinical outcomes and hospital length of stay. Psychosomatics. 2002;43(1):24-30.

33. Compton MT, Craw J, Rudisch BE. Determinants of inpatient psychiatric length of stay in an urban county hospital. Psychiatry Q. 2006;77(2):17388.

34. Blais MA, Matthews J, Lipkis-Orlando R, Lechner E, Jacobo M, Lincoln R, Gulliver C, Herman JB, Goodman AF. Predicting length of stay on an acute care medical psychiatric inpatient service. Adm Policy Ment Health. 2003;31(1):15-29.

35. Creed F, Tomenson B, Anthony P, Tramner M. Predicting length of stay in psychiatry. Psychol Med. 1997;27(4):961-6.

36. Kirshner LA. Length of stay of psychiatric patients. A critical review and discussion. J Nerv Ment Dis. 1982;170(1):27-33.

37. Pepper B. Power and governance issues in general hospital psychiatry. Hosp Community Psychiatry. 1991;42(11):1169-72.

38. Hallak JE, Crippa JA, Vansan G, Zuardi AW. Diagnostic profile of inpatients as a determinant of length of stay in a general hospital psychiatric unit. Braz J Med Biol Res. 2003;36(9):1233-40. 